University of Michigan Law School University of Michigan Law School Scholarship Repository

1980

\title{
Machiavelli and the Bar: Ethical Limitations on Lying in Negotiation
}

James J. White

University of Michigan Law School, jjwhite@umich.edu

Available at: https://repository.law.umich.edu/articles/853

Follow this and additional works at: https://repository.law.umich.edu/articles

Part of the Dispute Resolution and Arbitration Commons, and the Legal Ethics and Professional Responsibility Commons

\section{Recommended Citation}

White, James J. "Machiavelli and the Bar: Ethical Limitations on Lying in Negotiation." Am. B. Found. Res. J. 1980 (1980): 926-38.

This Article is brought to you for free and open access by the Faculty Scholarship at University of Michigan Law School Scholarship Repository. It has been accepted for inclusion in Articles by an authorized administrator of University of Michigan Law School Scholarship Repository. For more information, please contact mlaw.repository@umich.edu. 


\title{
Machiavelli and the Bar: Ethical Limitations on Lying in Negotiation
}

\author{
James J. White
}

Upon the enactment of the Model Rules of Professional Conduct, published ethical norms will for the first time give explicit consideration to the lawyer's behavior in the process of negotiation. Rules 4.1, 4.2, and 4.3 deal with negotiation. Although the Canons, the interpretations of the Canons, and the Disciplinary Rules and Ethical Considerations gave tangential consideration to negotiating, ${ }^{1}$ none of the Disciplinary Rules or Ethical Considerations explicitly considered negotiation apart from the process of litigation or counseling. The mere recognition of negotiation as a separate process worthy of unique rules is a large step. The purpose of this paper is to address the general question of truthfulness as that question is faced in Rule 4.2. ${ }^{2}$

The difficulty of proposing acceptable rules concerning truthfulness in negotiation is presented by several circumstances. First, negotiation is nonpublic behavior. If one negotiator lies to another, only by happenstance will the other discover the lie. If the settlement is concluded by negotiation, there will be no trial, no public testimony by conflicting witnesses, and thus no opportunity to examine the truthfulness of assertions made during the negotiation. Consequently, in negotiation, more than in other contexts, ethical norms can probably be violated with greater confidence that there will be no discovery and punishment.

James J. White is Professor of Law, University of Michigan Law School. B.A., 1956, Amherst College; J.D., 1962, Michigan.

1. See, e.g., ABA Code of Professional Responsibility DR 7-102(A) and DR 1-102(A) ("A lawyer shall not: . . . (4) [e]ngage in conduct involving dishonesty, fraud, deceit, or misrepresentation."). American Bar Association, Committee on Ethics and Professional Responsibility, Model Code of Professional Responsibility and Code of Judicial Conduct (Chicago: American Bar Association, 1979).

2. I note in passing one objectionable aspect of the proposed Rules that is unrelated to truthfulness. That is their gratuitous direction, in the Introduction and Comments, about how to behave in negotiation. For example, the Introduction has extensive discussion on what I would regard not as an ethical matter but as the substance of negotiating. It contains statements about the appropriate consideration of long-run as well as short-run interests, about whether one should behave in a "tough" or "hypertechnical" manner, and about other things that are matters of style, not of ethics. In my judgment, these are substantive negotiating questions that should be left to the judgment of the negotiator. They are no part of the responsibility of those making model rules for behavior in negotiation. One who is naturally a curmudgeon should not be thought less ethical than a person who is pleasant to deal with. One who is hypertechnical is not necessarily less ethical than a person who is willing to leave things to a handshake. Such discussion of style and substance of negotiation as opposed to the ethical behavior in negotiation seems gratuitous and inappropriate in the Model Rules and in the Comments to the Model Rules. 
Whether one is likely to be caught for violating an ethical standard says nothing about the merit of the standard. However, if the low probability of punishment means that many lawyers will violate the standard, the standard becomes even more difficult for the honest lawyer to follow, for by doing so he may be forfeiting a significant advantage for his client to others who do not follow the rules.

The drafters appreciated, but perhaps not fully, a second difficulty in drafting ethical norms for negotiators. That is the almost galactic scope of disputes that are subject to resolution by negotiation. One who conceives of negotiation as an alternative to a lawsuit has only scratched the surface. Negotiation is also the process by which one deals with the opposing side in war, with terrorists, with labor or management in a labor agreement, with buyers and sellers of goods, services, and real estate, with lessors, with governmental agencies, and with one's clients, acquaintances, and family. By limiting his consideration to negotiations in which a lawyer is involved in his professional role, one eliminates some of the most difficult cases but is left with a rather large and irregular universe of disputes. Surely society would tolerate and indeed expect different forms of behavior on the one hand from one assigned to negotiate with terrorists and on the other from one who is negotiating with the citizens on behalf of a governmental agency. ${ }^{3}$ The difference between those two cases illustrates the less drastic distinctions that may be called for by differences between other negotiating situations. Performance that is standard in one negotiating arena may be gauche, conceivably unethical, in another. More than almost any other form of lawyer behavior, the process of negotiation is varied; it differs from place to place and from subject matter to subject matter. It calls, therefore, either for quite different rules in different contexts or for rules stated only at a very high level of generality.

A final complication in drafting rules about truthfulness arises out of the paradoxical nature of the negotiator's responsibility. On the one hand the negotiator must be fair and truthful; on the other he must mislead his opponent. Like the poker player, a negotiator hopes that his opponent will overestimate the value of his hand. Like the poker player, in a variety of ways he must facilitate his opponent's inaccurate assessment. The critical difference between those who are successful negotiators and those who are not lies in this capacity both to mislead and not to be misled.

Some experienced negotiators will deny the accuracy of this assertion, but they will be wrong. I submit that a careful examination of the behavior of even the most forthright, honest, and trustworthy negotiators will show them actively engaged in misleading their opponents about their true positions. ${ }^{4}$ That is true of both the plaintiff and the defendant in a lawsuit. It is true of both labor and

3. For a discussion of the circumstances that might justify a lie, even for one with an extraordinary commitment to truthfulness, see Sissela Bok, ch. 8, Lies in a Crisis in Lying: Moral Choice in Public and Private Life 107-22 (New York: Pantheon Books, 1978).

4. Karrass states flatly that "bluffing is part of negotiating." Moreover, he instructs one to make offers that the opponent must refuse in order to make later offers look good by comparison. Chester Louis Karrass, Give and Take: The Complete Guide to Negotiating Strategies and Tactics 23, 107 (New York: Thomas Y. Crowell Co., 1974), and id., The Negotiating Game: How to Get What You Want 187 (New York: Thomas Y. Crowell Co., 1970). 
management in a collective bargaining agreement. It is true as well of both the buyer and the seller in a wide variety of sales transactions. To conceal one's true position, to mislead an opponent about one's true settling point, is the essence of negotiation.

Of course there are limits on acceptable deceptive behavior in negotiation, but there is the paradox. How can one be "fair" but also mislead? Can we ask the negotiator to mislead, but fairly, like the soldier who must kill, but humanely?

\section{Truthtelling in General}

The obligation to behave truthfully in negotiation is embodied in the requirement of Rule 4.2(a) that directs the lawyer to "be fair in dealing with other participants." Presumably the direction to be fair speaks to a variety of acts in addition to truthfulness and also different from it. At a minimum it has something to say about the threats a negotiator may use, ${ }^{5}$ about the favors he may offer, ${ }^{6}$ and possibly about the extraneous factors other than threats and favors which can appropriately be used in negotiating. ' As I have suggested elswhere, each of these issues has important ramifications, and each merits independent consideration by the drafters of the Model Rules and by lawyers. In this paper I ignore those questions and limit my consideration to the question of truth telling.

The comment on fairness under Rule 4.2 makes explicit what is implicit in the rule itself by the following sentence: "Fairness in negotiation implies that representations by or on behalf of one party to the other party be truthful." Standing alone that statement is too broad. Even the Comments contemplate activities such as puffing which, in the broadest sense, are untruthful. ${ }^{3}$ It seems quite

5. It is obvious that threats are important parts of much negotiation-the threat to go to trial, the threat to go to war, the threat to do a variety of other acts. In itself an implicit or explicit threat is often neither unethical nor illegal. But it is easy to think of threats that are either unethical or illegal, or both. For example, a threat of criminal prosecution in return for the settlement of civil litigation is normally thought to be both unethical and in violation of the criminal law. It would be useful to have someone outline the appropriate bounds of negotiating behavior here. For a consideration of some of the problems, see Joseph M. Livermore, Lawyer Extortion, 20 Ariz. L. Rev. 403 (1978).

6. See generally Harry T. Edwards \& James J. White, Problems, Readings and Materials on the Lawyer as a Negotiator 416-19 (St. Paul, Minn.: West Publishing Co., 1977). There we consider a variety of problems that deal with the questions what favors are appropriate and what factors extraneous to the negotiation may properly be used. The favors one might offer to an opposing negotiator range all the way from a martini through a golf outing to some other form of entertainment that involves considerable expense. Of course, the ethical problem here is not unique to negotiation, but it is important for negotiators.

7. Lawyer writings on negotiation are full of instructions to time one's settlement offer to coincide with the opposing lawyer's need for money to pay his taxes or for the use of other factors extraneous to the negotiation itself. Obviously, many factors other than the objective merit of the opponent's case will be factors in the negotiation. An obvious example, unrelated to the merits of the case of the opposing party but one highly important in the negotiation, is the skill of the lawyer that the opposing client has hired. If he is the best trial lawyer in the city, the settlement value of his case will go up. If he is a lawyer known to be afraid of the courthouse, the settlement value will go down. Surely every lawyer would be expected to use that in negotiating a settlement, but if one takes a step or two beyond that simple calculation based on lawyer skill one finds himself on uncertain ground. See also Edwards \& White, supra note 6, at 416-19.

8. See, e.g.,:

A party is permitted to suggest advantages to an opposing party that may be insubstantial from an objective point of view. The precise contours of the legal duties concerning disclosure, representation, puffery, overreaching, and other aspects of honesty in negotiations cannot be concisely stated. . . . It is a lawyer's re- 
unlikely that the drafters intend or can realistically hope to outlaw a variety of other nontruthful behavior in negotiations. Below we will consider some examples, but for the time being we will consider the complexity of the task.

Pious and generalized assertions that the negotiator must be "honest" or that the lawyer must use "candor" are not helpful.9 They are at too high a level of generality, and they fail to appreciate the fact that truth and truthful behavior at one time in one set of circumstances with one set of negotiators may be untruthful in another circumstance with other negotiators. There is no general principle waiting somewhere to be discovered as Judge Alvin B. Rubin seems to suggest in his article on lawyer's ethics. ${ }^{10}$ Rather, mostly we are doing what he says we are not doing, namely, hunting for the rules of the game as the game is played in that particular circumstance.

The definition of truth is in part a function of the substance of the negotiation. " Because of the policies that lie behind the securities and exchange laws and the demands that Congress has made that information be provided to those who buy and sell, one suspects that lawyers engaged in SEC work have a higher standard of truthfulness than do those whose agreements and negotiations will not affect public buying and selling of assets. Conversely, where the thing to be bought and sold is in fact a lawsuit in which two professional traders conclude the deal, truth means something else. Here truth and candor call for a smaller amount of disclosure, permit greater distortion, and allow the other professional to suffer from his own ignorance and sloth in a way that would not be acceptable in the SEC case. In his article Rubin recognizes that there are such different perceptions among members of the bar engaged in different kinds of practice, and he suggests that there should not be such differences. ${ }^{12}$ Why not? Why is it

sponsibility to see that negotiations conducted by the lawyer conform to applicable legal standards, what-

ever they may be.

From Comment to Rule 4.2, American Bar Association, Commission on Evaluation of Professional Standards, Model Rules of Professional Conduct 89-90 (Discussion Draft, Chicago: American Bar Association, Jan. 30, 1980).

9. See, e.g., Canon 22 of the Canons of Professional Ethics, in American Bar Association, Opinions of the Committee on Professional Ethics with the Canons of Professional Ethics Annotated and Canons of Judicial Ethics Annotated (Chicago: American Bar Foundation, 1967). "The conduct of the lawyer before the Court and with other lawyers should be characterized by candor and fairness." See also L. Ray Patterson \& Elliott E. Cheatham, The Profession of Law 123 (Mineola, N.Y.: Foundation Press, 1971).

10. Rubin states his position as follows:

The lawyer must act honestly and in good faith. Another lawyer, or a layman, who deals with a lawyer should not need to exercise the same degree of caution that he would if trading for reputedly antique copper jugs in an oriental bazaar. It is inherent in the concept of an ethic, as a principle of good conduct, that it is morally binding on the conscience of the professional, and not merely a rule of the game adopted because other players observe (or fail to adopt) the same rule.

Alvin B. Rubin, A Causerie on Lawyers' Ethics in Negotiation, 35 La. L. Rev. 577, 589 (1975).

11. See, e.g., Bok, supra note 3, at 138.

12. Rubin writes:

The esteem of a lawyer for his own profession must be scant if he can rationalize the subclassifications this distinction implies. . . .

Lawyers from Wall Street firms say that they and their counterparts observe scrupulous standards, but they attribute less morality to the personal injury lawyer, and he, in turn, will frequently point out the inferiority of the standards of those who spend much time in criminal litigation. The gradation of the ethics of 
so clear that one's responsibility for truth ought not be a function of the policy, the consequences, and the skill and expectations of the opponent? ${ }^{13}$

Apart from the kinds of differences in truthfuiness and candor which arise from the subject matter of the negotiation, one suspects that there are other differences attributable to regional and ethnic differences among negotiators. ${ }^{14} \mathrm{Al}$ though I have only anecdotal data to support this idea, it seems plausible that one's expectation concerning truth and candor might be different in a small, homogeneous community from what it would be in a large, heterogeneous community of lawyers. For one thing, all of the lawyers in the small and homogeneous community will share a common ethnic and environmental background. Each will have been subjected to the same kind of training about what kinds of lies are appropriate and what are not appropriate.

Moreover, the costs of conformity to ethical norms are less in a small community. Because the community is small, it will be easy to know those who do not conform to the standards and to protect oneself against that small number. Conversely, in the large and heterogeneous community, one will not have confidence either about the norms that have been learned by the opposing negotiator or about his conformance to those norms.

The differences that may result in perceptions about "truth and candor" often come to the surface in my negotiations seminar at the Michigan Law School, where there will be students from all parts of the country, from large and small cities, and from a variety of ethnic backgrounds. One such seminar involved a discussion between two students who had engaged in a mock negotiation that had been heated and had resulted in an unsatisfactory outcome for both. Each student had grown up in Manhattan; one was black, the other was Jewish. Their discussion in the seminar about their personal reactions to negotia-

the profession by the area of law becomes curiouser and curiouser the more it is examined, if one may purloin the words of another venturer in wonderland.

Rubin, supra note 10 , at 583-84.

13. Consider our hypothetical concerning distortion of the value of a piece of property in a negotiation with a lawyer who is presumed to know his business or, alternatively, with an aged and ignorant owner. The students in my negotiation seminar routinely will find exaggeration and distortion to be inappropriate when one is dealing with the layman, but to be at least ethical if not wise behavior when dealing with an opposing lawyer. See generally Edwards \& White, supra note 6, at 418-19.

14. For a consideration of some of the deviations in negotiating behavior arising out of cultural differences, consider the following excerpt from Hall \& Whyte, Intercultural Communication: $A$ Guide to Men of Action, 19 Human Organization 5-12 (1960):

In Latin America, you should expect to spend hours waiting in outer offices. If you bring your American interpretation of what constitutes punctuality to a Latin-American office, you will fray your temper and elevate your blood pressure. For a forty-five-minute wait is not unusual-no more unusual than a five minute wait would be in the United States. No insult is intended. . . . [t] the time pie is differently cut, that's all.

. . . In America, we show good faith by ignoring the details. "Let's agree on the main points. The details will take care of themselves." Not so the Greek. He signifies good will and good faith by what may seem to you an interminable discussion which includes every conceivable detail. Otherwise, you see, he cannot help but feel that the other man might be trying to pull the wool over his eyes. Our habit, in what we feel to be our relaxed and friendly way, of postponing details until later smacks the Greek between the eyes as a maneuver to flank him.

The American desire to get down to business . . . works to our disadvantage in other parts of the world. . . . The head of a large, successful Japanese firm commented: "You Americans have a terrible weakness. We Japanese know about it and exploit it every chance we get. You are impatient. We have learned that if we just make you wait long enough, you'll agree to anything."

.. Not only is our idea of time schedules no part of Arab life but the mere mention of a deadline to an Arab is like waving a red flag in front of a bull. In his culture, your emphasis on a deadline has the emotional effect on him that his backing you into a corner and threatening you with a club would have on you. 
tion, about their experience as children and young adults in the art of negotiation, and about their personal reactions to it was illuminating. The Jewish student, one of the best in the class, was more at ease with the negotiation process, more comfortable with the ambiguity it produced, and more experienced as a negotiator. The black student, also a good student, reported that an extended negotiation without some event to relieve the tension caused him tremendous anxiety. He reported that his youthful negotiations were short and often concluded in explosive behavior. For example, if there were an argument about where two groups would play baseball (on my lot or yours), the typical negotiation would last a few minutes and, if it were not quickly resolved, would be concluded by a fight. At the conclusion of that fight the game would be played on the winner's lot. Although the anecdote does not show systematic ethical differences between the two students, it does reveal systematically different attitudes about the negotiation process as a whole, and there is no reason to believe that there are not similar and systematic differences about the appropriate level of candor and honesty among the various ethnic and regional subgroups in our society. That is not to say that one norm is correct, only that the rules of the game played by one group are not the same as the rules played by another.

If the Comments or the body of the Model Rules are to refer to truthfulness, they should be understood to mean not an absolute but a relative truth as it is defined in context. That context in turn should be determined by the subject matter of the negotiation and, to a lesser extent, by the region and the background of the negotiators. Of course, such a flexible standard does not resolve the difficulties that arise when negotiators of different experience meet one another. I despair of solving that problem by the promulgation of rules, for to do so would require the drafters of these rules to do something that they obviously could not wish to do. That is, unless they wish to rely on the norms in the various subcultures in the bar to flesh out the rules, they will have to draft an extensive and complex body of rules.

\section{Five Cases}

Although it is not necessary to draft such a set of rules, it is probably important to give more than the simple disclaimer about the impossibility of defining the appropriate limits of puffing that the drafters have given in the current Comments. ${ }^{15}$ To test these limits, consider five cases. Easiest is the question that arises when one misrepresents his true opinion about the meaning of a case or a statute. Presumably such a misrepresentation is accepted lawyer behavior both in and out of court and is not intended to be precluded by the requirement that the lawyer be "truthful." In writing his briefs, arguing his case, and attempting to persuade the opposing party in negotiation, it is the lawyer's right and probably his responsibility to argue for plausible interpretations of cases and statutes which favor his client's interest, even in circumstances where privately he has ad- 
vised his client that those are not his true interpretations of the cases and statutes.

A second form of distortion that the Comments plainly envision as permissible is distortion concerning the value of one's case or of the other subject matter involved in the negotiation. Thus the Comments make explicit reference to "puffery." draws in commercial law between express warranties and "mere puffing" under section 2-313 of the Uniform Commercial Code. ${ }^{17}$ While this line is not easy to draw, it generally means that the seller of a product has the right to make general statements concerning the value of his product without having the law treat those statements as warranties and without having liability if they turn out to be inaccurate estimates of the value. As the statements descend toward greater and greater particularity, as the ignorance of the person receiving the statements increases, the courts are likely to find them to be not puffing but express warranties. ${ }^{18}$ By the same token a lawyer could make assertions about his case or about the subject matter of his negotiation in general terms, and if those proved to be inaccurate, they would not be a violation of the ethical standards. Presumably such statements are not violations of the ethical standards even when they conflict with the lawyer's dispassionate analysis of the value of his case.

A third case is related to puffing but different from it. This is the use of the so-called false demand. It is a standard negotiating technique in collective bargaining negotiation and in some other multiple-issue negotiations for one side to include a series of demands about which it cares little or not at all. ${ }^{19}$ The purpose of including these demands is to increase one's supply of negotiating currency. One hopes to convince the other party that one or more of these false demands is important and thus successfully to trade it for some significant concession. The assertion of and argument for a false demand involves the same kind of distortion that is involved in puffing or in arguing the merits of cases or statutes that are not really controlling. The proponent of a false demand implicitly or explicitly states his interest in the demand and his estimation of it. Such behavior is untruthful in the broadest sense; yet at least in collective bargaining negotiation its use is a standard part of the process and is not thought to be inappropriate by any experienced bargainer.

Two final examples may be more troublesome. The first involves the response of a lawyer to a question from the other side. Assume that the defendant has instructed his lawyer to accept any settlement offer under $\$ 100,000$. Having re-

16. Id.

17. Section 2-313(2) of the Uniform Commercial Code reads in part as follows: "It is not necessary to the creation of an express warranty that the seller use formal words . . . but an affirmation merely of the value of the goods or a statement purporting to be merely the seller's opinion or commendation . . . does not create a warranty." Put another way, puffing is permitted.

18. Compare Wat Henry Pontiac Co. v. Bradley, 202 Okla. 82, 210 P.2d 348 (1949) (statement about a used car to a woman who was to drive with her young child to visit her husband in the service held an express warranty) with Frederickson v. Hackney, 159 Minn. 234, 198 N.W. 806 (1924) (extravagant statement to wary farmer about the quality of a young bull held not a warranty).

19. "A typical strategy used by most unions at one time or another is to bury two or three serious fringe objectives in a veritable mountain of fringe demands-as many as twenty-five, thirty, and more." Edward Peters, Strategy and Tactics in Labor Negotiations 165 (New London, Conn.: Foremen's Institute, 1955). 
ceived that instruction, how does the defendant's lawyer respond to the plaintiff's question, "I think $\$ 90,000$ will settle this case. Will your client give $\$ 90,000$ ?" Do you see the dilemma that question poses for the defense lawyer? It calls for information that would not have to be disclosed. A truthful answer to it concludes the negotiation and dashes any possibility of negotiating a lower settlement even in circumstances in which the plaintiff might be willing to accept half of $\$ 90,000$. Even a moment's hesitation in response to the question may be a nonverbal communication to a clever plaintiff's lawyer that the defendant has given such authority. Yet a negative response is a lie.

It is no answer that a clever lawyer will answer all such questions about authority by refusing to answer them, nor is it an answer that some lawyers will be clever enough to tell their clients not to grant them authority to accept a given sum until the final stages in negotiation. Most of us are not that careful or that clever. Few will routinely refuse to answer such questions in cases in which the client has granted a much lower limit than that discussed by the other party, for in that case an honest answer about the absence of authority is a quick and effective method of changing the opponent's settling point, and it is one that few of us will forego when our authority is far below that requested by the other party. Thus despite the fact that a clever negotiator can avoid having to lie or to reveal his settling point, many lawyers, perhaps most, will sometime be forced by such a question either to lie or to reveal that they have been granted such authority by saying so or by their silence in response to a direct question. Is it fair to lie in such a case? ${ }^{20}$

Before one examines the possible justifications for a lie in that circumstance, consider a final example recently suggested to me by a lawyer in practice. There the lawyer represented three persons who had been charged with shoplifting. Having satisfied himself that there was no significant conflict of interest, the defense lawyer told the prosecutor that two of the three would plead guilty only if the case was dismissed against the third. Previously those two had told the defense counsel that they would plead guilty irrespective of what the third did, and the third had said that he wished to go to trial unless the charges were dropped. Thus the defense lawyer lied to the prosecutor by stating that the two would plead only if the third were allowed to go free. Can the lie be justified in this case? 21

How does one distinguish the cases where truthfulness is not required and

20. Mr. Curtis might have authorized a lie in this case and may well have justified it on the basis suggested:

It may be that it all depends on whether you are asked the question by someone who has a right to ask it. If he has no right to ask and if simple silence would, or even might, lead him to the truth, then, 1 believe your lawyer is in duty bound to lie. For the truth is not his, but yours. It belongs to you and he is bound to keep it for you, even more vigorously than if it were only his own.

Charles P. Curtis, The Ethics of Advocacy, 4 Stanford L. Rev. 3, 8 (1951). Bok waffles on these issues but would appear not to support a lie in such circumstances. Compare Bok, supra note 3, at 160 with her discussion at 167 and 171-73.

21. Consider a variation on the last case. Assume that the defense lawyer did not say explicitly that the two would plead only if the third were allowed to go free but simply said, "If you drop the charges against one, the other two will plead guilty." In that case the lie is not explicit but surely the inference which the defense lawyer wishes the prosecutor to draw is the same. Should that change the outcome? 
those where it is required? Why do the first three cases seem easy? I suggest they are easy cases because the rules of the game are explicit and well developed in those areas. Everyone expects a lawyer to distort the value of his own case, of his own facts and arguments, and to deprecate those of his opponent. No one is surprised by that, and the system accepts and expects that behavior. To a lesser extent the same is true of the false demand procedure in labor-management negotiations where the ploy is sufficiently widely used to be explicitly identified in the literature. A layman might say that this behavior falls within the ambit of "exaggeration," a form of behavior that while not necessarily respected is not regarded as morally reprehensible in our society.

The last two cases are more difficult. In one the lawyer lies about his authority; in the other he lies about the intention of his clients. It would be more difficult to justify the lies in those cases by arguing that the rules of the game explicitly permit that sort of behavior. Some might say that the rules of the game provide for such distortion, but I suspect that many lawyers would say that such lies are out of bounds and are not part of the rules of the game. Can the lie about authority be justified on the ground that the question itself was improper? Put another way, if I have a right to keep certain information to myself, and if any behavior but a lie will reveal that information to the other side, am I justified in lying? I think not. Particularly in the case in which there are other avenues open to the respondent, should we not ask him to take those avenues? That is, the careful negotiator here can turn aside all such questions and by doing so avoid any inference from his failure to answer such questions.

What makes the last case a close one? Conceivably it is the idea that one accused by the state is entitled to greater leeway in making his case. ${ }^{22}$ Possibly one can argue that there is no injury to the state when such a person, particularly an innocent person, goes free. Is it conceivable that the act can be justified on the ground that it is part of the game in this context, that prosecutors as well as defense lawyers routinely misstate what they, their witnesses, and their clients can and will do? None of these arguments seems persuasive. Justice is not served by freeing a guilty person. The system does not necessarily achieve better results by trading two guilty pleas for a dismissal. Perhaps its justification has its roots in the same idea that formerly held that a misrepresentation of one's state of mind was not actionable for it was not a misrepresentation of fact.

In a sense rules governing these cases may simply arise from a recognition by the law of its limited power to shape human behavior. By tolerating exaggeration and puffing in the sales transaction, by refusing to make misstatement of one's intention actionable, the law may simply have recognized the bounds of its control over human behavior. Having said that, one is still left with the question, Are the lies permissible in the last two cases? My general conclusion is that they are not, but I am not nearly as comfortable with that conclusion as I am with the conclusion about the first three cases.

Taken together, the five foregoing cases show me that we do not and cannot intend that a negotiator be "truthful" in the broadest sense of that term. At the minimum we allow him some deviation from truthfulness in asserting his true

22. See, e.g., Rule 4.2(b)(2) and Rule 3.1(f), Model Rules, supra note 8. 
opinion about cases, statutes, or the value of the subject of the negotiation in other respects. In addition some of us are likely to allow him to lie in response to certain questions that are regarded as out of bounds, and possibly to lie in circumstances where his interest is great and the injury seems small. It would be unfortunate, therefore, for the rule that requires "fairness" to be interpreted to require that a negotiator be truthful in every respect and in all of his dealings. It should be read to allow at least those kinds of untruthfulness that are implicitly and explicitly recognized as acceptable in his forum, a forum defined both by the subject matter and by the participants.

\section{Mandatory Disclosure}

Model Rule 4.2(b) requires the lawyer "to disclose a material fact known to the lawyer, even if adverse, when disclosure is . . . necessary to correct a manifest misapprehension of fact or law resulting from a previous representation made by the lawyer or known by the lawyer to have been made by the client . . . ." Elsewhere the rules make clear that one must make such a disclosure even though he is disclosing facts that would otherwise be privileged and that he would otherwise be prohibited from disclosing because of Rule 1.7. The rule is clear and explicit; it unequivocally resolves conflict between client confidentiality and disclosure. For that the drafters should be commended. ${ }^{23}$ More important, the drafters are right.

To those who value the privilege more highly than the drafters and who think it sacrilegious to suggest that a lawyer should disclose his client's confidence, consider the anomalies that result if the lawyer is not required to speak up. Assume, for example, that the lawyer for a tenant has negotiated a $\$ 2,000$ settlement with the landlord's lawyer. Assume that the dispute arose when the tenant's apartment was burglarized and that the settlement was based on the assertion by the tenant that the landlord was negligent in maintaining the locks. Assume, however, that the settlement was based on figures that had been relayed orally by the tenant client to his lawyer. Subsequently the tenant brings a receipt showing that a missing stereo was purchased for $\$ 200$, although the tenant has now altered the receipt to show a $\$ 1,500$ purchase price. The $\$ 2,000$ settlement offer was based on that altered price. Obviously the landlord's lawyer would not have offered a $\$ 2,000$ settlement had he known that the stereo was worth only $\$ 200$ and not $\$ 1,500$. It is a material misrepresentation that would allow any agreement to be overturned on the grounds of fraud or mistake. Would it not be anomalous, then, if the rule said to the lawyer, "You must accept this settlement or at most you can resign, but because these were privileged documents and privileged information you may not disclose them to the other side"'? Such a rule would require a lawyer to facilitate an agreement that, if the facts were known, would be unenforceable. Rule 4.2 would require the lawyer to come forward and to tell the other side the stereo's true price.

Consider two other cases where the rule will come into play. One is the situa-

23. Rule 1.7(b) provides: "A lawyer shall disclose information about a client . . . to the extent required by law or the Rules of Professional Conduct." The Comments refer explicitly to Rule 4.2, and the quoted language is apparently intended to resolve the conflict in favor of disclosure when the lawyer learns that his client has lied or otherwise misrepresented facts to the opposing side. See Comment on mandatory disclosure, Model Rules, supra note 6, at 26. 
tion in which a client has stated certain facts on a deposition and then concedes to his lawyer that they are not true, or it comes to the lawyer's attention by other means that they are not true. In such circumstances the lawyer would have to disclose that to the opposing party. ${ }^{24}$ The same rule would apply if at an early stage in a negotiation one party had relied on a case that was subsequently overruled or on a statute that was repealed. ${ }^{25}$

There are two difficulties with the rule; one of them may be a major difficulty. First and least important is to determine how to measure when a "manifest misapprehension" has occurred. Consider, for example, the case widely used in mock negotiation by lawyers and law students in which a mechanic testifies on the deposition that his customer (the father of a child who was killed in an auto accident after the mechanic worked on the car) did not request that the mechanic check the brakes but asked only for a "general checkup" of the car. Subsequently the mechanic comes to his lawyer and states that he "remembers" that the father of the dead child did tell him to check the brakes. To me that has always seemed a straightforward case for this rule, one in which the witness lied initially, subsequently was overcome with remorse, and confessed to his lawyer. There is another plausible hypothesis that has been suggested to me by my colleague Andrew S. Watson, whose specialty is psychiatry and law, and by various lawyers who have negotiated the problem. That is the hypothesis that the mechanic testified truthfully the first time that he had in fact not been ordered to check the brakes, but that his sense of guilt at being even remotely connected with the death of the child caused him subsequently to believe incorrectly and to state inaccurately that he had been instructed to check the brakes. How is the lawyer to behave in such a case? If he adopts the latter interpretation, there is no misrepresentation and he need not come forward. If he adopts the former interpretation, the case falls squarely within $4.2(b)$. The rule will present a series of other linedrawing problems in determining whether or not the fact was "material" and in determining whether it "resulted" from a previous representation by the lawyer or his client. Finally, as in the hypothetical case, there will be the question what is a manifest misapprehension. Doubtless these difficulties are inherent in any

24. In this context Rule 4.2 asks the lawyer to do no more than Rule 26(e) of the Federal Rules of Civil Procedure would require. Although that rule requires supplementation of a party's deposition when he "obtains information" that leads him to "know" that the earlier response was incorrect, it undoubtedly also includes cases in which the party lied in the first instance and thus "knew" all along that his response was incorrect. Rule 26(e) reads as follows;

A party who has responded to a request for discovery with a response that was complete when made is under no duty to supplement his response to include information thereafter acquired, except as follows:

(2) A party is under a duty seasonably to amend a prior response if he obtains information upon the basis of which (A) he knows that the response was incorrect when made, or (B) he knows that the response though correct when made is no longer true and the circumstances are such that a failure to amend the response is in substance a knowing concealment.

See also Charles Alan Wright \& Arthur R. Miller, 8 Federal Practice and Procedure $§ 2049$ (St. Paul, Minn.: West Publishing Co., 1970).

25. One might argue that a representation about a case does not produce "a manifest misapprehension of . . . law resulting from a previous representation." A misapprehension, so the argument goes, results from the failure of the opposing lawyer to Shepardize the cases and to determine that the one relied on was subsequently overruled. I think that reads the rule too narrowly and that at least in cases in which there is a central case that one party has cited in the negotiations and has relied on, that party has an obligation upon its overruling on appeal to correct his opponent's understanding. 
rules of the kind proposed, and if we are to have such a rule, we will have to tolerate substantial deviation in its application and use by lawyers based on their individual interpretations of these words.

A more troublesome difficulty with the rule, and one related to the first, is that it may be so widely violated that it ought not be enacted. It is my hypothesis that it is better to have no rule than to have one so widely violated as to be a continuing hypocrisy that may poison the application of the remaining rules. It is conceivable that Rule 4.2(b) is such a rule. In the first place the rule runs up against the traditional and deep-seated idea that the lawyer has a single-minded commitment to his client's case. Like many of the rules it also conflicts with the lawyer's desire to win, with his own identification with his client's case. Of course, lawyers who are so bound up with their clients' cases are not exemplars, but the rules are designed to deal with the mine run as well as the exemplary lawyer. Thus the rule calls on the lawyer not only to squeal on his client but, worse, to destroy a winner for himself and his client.

Of course, it is in the nature of compliance with ethical norms that one's selfinterest is often injured, but there must be a trade-off between compliance and injury to one's self-interest. If the latter is too great, few will follow the rules. If any significant part of the rules is routinely violated by a majority of the bar, that in turn weakens the structure of all the rules and makes it difficult to sustain a commitment of the organized bar to following and enforcing those rules. Whether the proposed rule concerning revelations of clients' misstatements and misrepresentations is a rule that would be so widely violated that it should not be enacted I cannot say. From presenting the problem I described above to several hundreds of lawyers and discussing that problem afterward, I am confident that a majority of the lawyers operating under today's rules would not reveal the fact that the client had recanted his deposition in a negotiation with the other party. My observation of those lawyers suggests that the most common position is one in which the lawyer will no longer use the mechanic's assertion affirmatively but will not admit that the mechanic has recanted the position he took on the deposition. ${ }^{26}$

Do these anecdotal data suggest that lawyers in general will not follow the

26. One rarely hears of a lawyer revealing a client's lie despite the current DR 7-102(B), which reads as follows:

A lawyer who receives information clearly establishing that:

(1) His client has, in the course of the representation, perpetrated a fraud upon a person or tribunal shall promptly call upon his client to rectify the same, and if his client refuses or is unable to do so, he shall reveal the fraud to the affected person or tribunal, except when the information is protected as a privileged communication.

ABA Code of Professional Responsibility, supra note 1.

Presumably the failure to come forward in this case would be justified by a lawyer's argument either that the information did not "clearly" establish that fraud had been perpetrated or that the information was privileged and thus could not be revealed. The rule is not clear because of the confusing cross-reference to DR 4-101 which authorizes a lawyer to reveal confidences or secrets "when permitted under Disciplinary Rules or required by law or court order."

Even if the lawyer concludes that he is not free to reveal his client's confidence because DR 4-101 limits DR 7-102(B), he should conclude that he could not use the lie affirmatively because to do so would violate DR 7-102(A)(2), (4), (5), and possibly other subsections.

Note in the hypothetical case I have assumed that the employee of an insured is nevertheless the "client" of the lawyer whose fee will in fact be paid by an insurance company. 
rule? At least it should give pause. It is conceivable that lawyers would change their attitude if a rule as explicit and straightforward as the one proposed were enacted and if there were an effective means to inform the bar at large about such a rule.

In summary, I support Rule 4.2(b), but I think the drafters need to realize that by enacting that rule together with some of the others that are proposed we are asking lawyers to deviate from the traditional American attitude that the lawyer is identified with his client's interest and is obliged to protect privileged information. Because such a rule asks the lawyer not only to act contrary to his selfish interests but also to violate the important psychological association with his client and his client's case, the drafters are undertaking a difficult chore. In their consideration of this rule, the drafters must take account of that question and of the probability that lawyers will be willing to conform to such a rule. If they conclude that a substantial minority of the lawyers who know such a rule will nevertheless violate it, that alone is sufficient basis for not enacting such a rule.

\section{Conclusion}

To draft effective legislation is difficult; to draft effective ethical rules is close to impossible. Such drafters must walk the narrow line between being too general and too specific. If their rules are too general, they will have no influence on any behavior and give little guidance even to those who wish to follow the rules. If they are too specific, they omit certain areas or conflict with appropriate rules for problems not foreseen but apparently covered.

There are other, more formidable obstacles. These drafters are essentially powerless. They draft the rules, but the American Bar Association must pass them, and the rules must then be adopted by various courts or other agencies in the states. Finally the enforcement of the rules is left to a hodgepodge of bar committees and grievance agencies of varied will and capacity. Thus the drafters are far removed from and have little control over those who ultimately will enact and enforce the rules. For that reason, even more than most legislators, drafters of ethical rules have limited power to influence behavior. This weakness presents a final dilemma and one they have not always faced as well as they should, namely, to make the appropriate trade-off between what is "right" and what can be done. To enact stern and righteous rules in Chicago will not fool the people in Keokuk. The public will not believe them, and the bar will not follow them. What level of violation of the rules can the bar accept without the rules as a whole becoming a mockery? I do not know and the drafters can only guess. Because of the danger presented if the norms are widely and routinely violated, the drafters should err on the conservative side and must sometimes reject better and more desirable rules for poorer ones simply because the violation of the higher standard would cast all the rules in doubt. 